\title{
LA ESCUELA DE PADRES, \\ UN TESTIMONIO \\ DE MODELO DE ÉXITO
}

Jaime Marcolino Barreiro González

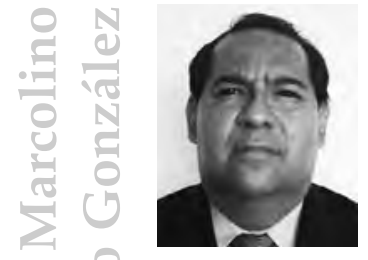

Estudiante de doctorado en Educación, Universidad Marista, Guadalajara. Maestro en Ciencias de la Educación con especialidad en Pedagogía, Instituto de Investigación y Docencia para el Magisterio. Licenciado en Pedagogía, Universidad Panamericana. Director de Primaria del Centro Tecnológico y Deportivo Jarales A.C. y catedrático de la Universidad Marista de Guadalajara.

Correo electrónico: [msmartin@up.edu.mx].

La educación familiar es la base de la personalización de los individuos que conforman la sociedad.

Fermoso.

Es mi deseo compartir algunas reflexiones iniciales sobre los orígenes de las escuelas de padres y sus contenidos propuestos con la finalidad de poseer un panorama previo a la esencia de este escrito: la presentación de un modelo de escuela de padres que inició su operación en 1995 y que sigue operando con éxito en varias ciudades de la República Mexicana y en otras de América Latina.

Espero sinceramente que sirva como testimonio de la gran aportación que los padres y madres de hoy pueden llevar a cabo al comprometerse con el proyecto educativo de la escuela. 
A lo largo de la historia, afirma el común de las personas: «Los padres han dejado buenos y malos recuerdos» ${ }^{1}$. Los buenos recuerdos, se originan en unas acciones determinadas — de papá o mamá-que dejan en el hijo la satisfacción, la alegría, el ejemplo, la motivación por ser mejor, por hacer mejor. Los malos recuerdos vienen a la memoria por acciones contrarias: los castigos, las llamadas de atención, los enojos por ciertos comportamientos y por pensar contrariamente a los padres.

Por estas acciones, los hijos forjan un buen o mal recuerdo de sus padres, y por ellas también son juzgados como buenos o malos padres. Ello no en el sentido moral, sino en la eficacia de su acción educativa. Esto es la base de la educación familiar: la tradición de buenas acciones de padres a hijos ${ }^{2}$.

Estas acciones eficaces forman «la tradición familiar», es decir, los padres realizaron acciones que sus hijos ahora aplican cuando son padres y así sucesivamente. Se considera que esta tradición es, de alguna manera, análoga a la «escuela de padres» de los padres de hoy. Sin embargo, después de la segunda guerra mundial, esta tradición se vió afectada por todo el desarrollo científico de la posguerra: la importancia del niño, con su propia naturaleza (Montessori); el desarrollo de la psicología evolutiva (Gesell); las primeras experiencias afectivas del niño, como factores del desarrollo de la personalidad (Freud); el desarrollo cognitivo (Piaget); la inteligencia emocional (Coleman), entre muchos otros. Con estos nuevos conocimientos, la educación familiar, fundada en la tradición, comienza a tomar un giro diferente: de tradición a sistematización científica.

Según Morantinos: «Es en 1929, cuando madame Vérine, en un clima de defensa de los valores familiares, crea la escuela de padres, cuya máxima era: "unirse, instruirse, servir" ${ }^{3}$. Los cambios sociales que se dieron a finales de la década de los 50, el surgimiento del movimiento feminista,

Se entiende por esta expresión lo que, en la experiencia común de cualquier persona, se percibe como un buen o mal recuerdo. No se entiende en un sentido moral de juicio sobre la bondad o maldad de los actos de los padres.

Cfr. José Ma. Quintana, Pedagogía familiar, p. 34.

3 José Ma. Quintana, op. cit., p. 197. 
el fenómeno de la liberación sexual, la incorporación al trabajo profesional de la mujer y la consiguiente salida del trabajo del hogar, una sociedad más demandante de equidad en la participación de hombres y mujeres, hacen que la educación familiar sufra cambios: ¿Quién educa a los hijos, si la madre ahora trabaja fuera del hogar? Si se emplea porque hay necesidad de mayor ingreso para sostener a la familia, entonces ¿en qué momento atiende a los hijos? ¿Cómo participa ahora el padre, en la educación de sus hijos? Más aún, cuando en la familia sólo hay una persona para el ejercicio de la educación familiar, ¿cómo afecta esta realidad a su función educativa?

Las escuelas de padres se desarrollan más formalmente a partir de la década de los 60 y 70. Para la década entre 1980 y 1990, los programas de escuela de padres se operan de manera más ordinaria y común en gran parte de colegios tanto particulares como oficiales. De hecho, en la legislación vigente, la escuela de padres es obligatoria para todas las instituciones del sistema educativo jalisciense [Jalisco, México] y, por ende, es también obligación de los padres participar en ellas. Por otra parte, existen instituciones especializadas que se dedican a trabajar más de cerca con las familias en todos sus aspectos (entre ellos, el ejercicio de la autoridad y su relación con la autonomía de los hijos).

Las escuelas de padres, tienen como objetivo «la formación pedagógica de los padres» ${ }^{4}$. Por ello, los temas que conforman sus contenidos, podrían organizarse de la siguiente manera:

\section{BASES DE LA EDUCACIÓN FAMILIAR:}

1. Socialización de los hijos.

2. Conocimiento de la personalidad de los hijos.

3. Conocimiento de los hijos en las diferentes etapas del desarrollo.

\section{METODOLOGÍA DE LA EDUCACIÓN FAMILIAR:}

1. Estilos educativos de los padres y sus pautas de intervención.

2. La práctica educativa en la familia. 
3. Relaciones familiares y sus aspectos educativos.

4. Hermanos y abuelos en el contexto educativo.

\section{III. ÁMBITOS DE LA EDUCACIÓN DE LOS HIJOS:}

1. Educación de hábitos.

2. Educación moral, social y religiosa.

3. Educación de los valores y actitudes.

4. Educación afectiva y sexual.

5. Educación del carácter y personalidad.

6. Educación higiénica.

7. Educación cultural.

8. Educación de la amistad.

Ahora bien, ¿cómo podría organizarse una escuela de padres? Para responder a este planteamiento, contaré la experiencia realizada en una de las escuelas de nuestra ciudad [Guadalajara].

El director de la institución se dio a la tarea de conocer a los padres de familia que conforman la comunidad educativa (nivel primaria). Después de esta labor, hizo una invitación personal a un grupo de padres y madres de familia (un total de 20 personas, de un total de 180 alumnos; aproximadamente el $10 \%$ de la población).

El criterio de selección fue principalmente la identificación de los padres de familia con los ideales educativos de la institución. Este punto ha sido tomado de la psicología organizacional: "A mayor sentido de pertenencia, mayor sentido de responsabilidad y compromiso personal con la institución» ${ }^{5}$. Los padres de familia mostraban una seria ilusión porque sus hijos estuvieran en esa escuela. Ellos esperaban colaborar y apoyar la educación impartida ahí.

En la reunión se les explicó que se formaría un grupo de «monitores», es decir, personas que se encargarían de dirigir un equipo de trabajo para la implementación de la escuela de padres de la institución, para los

Cfr. Ma. Estebes, Desarrollo organizacional, cap. II. 
próximos diez años. ¿Para qué la conformación de equipos? ¿Quiénes los integrarían? Los monitores serían los encargados de un equipo de trabajo, conformado por catorce personas (lo ideal sería que fueran siete parejas; sin embargo, podrían ser personas sin pareja).

Ellos se encargarían de generar una «dinámica dirigida» sobre el tema planteado. Al término de la exposición, el conferencista proporcionaría unas preguntas para concretar lo expuesto en las diversas situaciones que cada equipo de trabajo asumiría. El monitor fungiría de guía del trabajo realizado por el equipo. Se generaría así la participación de los miembros, procurando conocerlos de manera personal y realizando actividades recreativas con la finalidad de integrarse todos como equipo y, principalmente, entusiasmarlos para perseverar en el proyecto a comenzar.

En la plática se les informaría que ellos vivirían un proceso de capacitación que comprendería los siguientes temas: I) Esencia de la educación familiar; II) características psicológicas de los niños en educación primaria; III) el método del caso; IV) características del aprendizaje de los adultos; V) dinámica de grupos, e VI) integración de equipos de trabajo.

Esta capacitación se impartiría por especialistas y se llevaría a cabo en un período de tres meses.

Durante la capacitación, la integración del grupo de monitores se fue dando de manera paulatina y, a su vez, se les hizo conscientes de que ellos podrían preparar algunos temas que se abordarían a lo largo del curso.

Este proceso se llevó a cabo durante el primer semestre del ciclo escolar, de tal manera que para finales de febrero se tenía ya capacitado el grupo de monitores. Terminada la capacitación, se diseñó el plan de promoción para que toda la comunidad educativa, así como los padres de nuevo ingreso, conocieran el programa de escuela de padres que se operaría en el siguiente ciclo escolar. Esta escuela de padres tendría un nombre propio que diera pertenencia a sus participantes. Se propusieron nombres y se diseñó la publicidad (folletos y posters) con el nombre propio de la escuela de padres, los temas que se abordarían, la duración, el día y hora de la reunión, así como las fechas de eventos trascendentales como 
magnas conferencias o convivencias de integración de los participantes del programa.

Se organizó un equipo de «economía», encargado de solventar los gastos de operación del programa. Los gastos serían independientes de los costos de la escuela. Considerando que su trabajo como monitores se realiza por interés personal, sólo se contempló el costo del material que se les entregaría a los participantes, así como el pago al conferencista. Los eventos de convivencia se organizarían de manera más próxima, con la finalidad de contar con las propuestas de los participantes.

A cada monitor se le asignó un grupo para darle seguimiento al plan de promoción. De manera constante, desde el mes de abril hasta el final del ciclo escolar, el monitor encargado del grupo, les hizo saber del programa mediante folletos, invitación personal y circulares personalizadas, hasta lograr que los padres se inscribieran al programa.

El programa se dividió en dos grandes grupos. Los padres de los grupos de $1^{\circ}$ a $3^{\circ}$ (programa de escuela de padres de primaria menor) y los de $4^{\circ}$ a $6^{\circ}$ (programa de escuela de padres de primaria mayor), considerando que los intereses y características psicológicas de los niños son diferentes en ambos grupos. La conferencia se impartía al grupo completo y en el trabajo de grupo se aplicaba el tema a los niños de esa edad. Cada grupo era homogéneo en cuanto que eran padres de niños de primaria menor o de primaria mayor.

El programa se operaba de la siguiente forma:

a) Día de reunión, los miércoles, por ser el día medio de la semana y en pleno trabajo escolar.

b) Horario: de 8:00 a 10:00 p.m.

c) Una vez cada dos semanas.

d) En cada sesión, cuatro monitores se encargaban de tener listo el material necesario para la conferencia y disponer lo que se proporcionaría en el receso para el momento de su servicio. 
Para dar un seguimiento a la operación de la escuela de padres, el grupo de monitores, en compañía del director, se reunían una vez al mes para analizar los resultados de las evaluaciones de los participantes de las sesiones del mes, y analizar el porcentaje de asistencia general y de cada grupo. En esta ocasión se contó con la participación de 120 personas, con una asistencia promedio de un $70 \%$ a lo largo de todo el programa. A nivel mensual, la asistencia llegó a tener en algunas sesiones un $50 \%$ a $45 \%$, por lo que el trabajo de los monitores a lo largo de la semana era estar en contacto con los miembros de su equipo y recordarles su asistencia para la siguiente sesión.

La sesión de trabajo estaba distribuida de la siguiente manera:

a) De 8:00 a 8:10, resolución de un cuestionario introductorio al tema, con la finalidad de que los padres se sensibilizaran sobre qué conocen acerca de él y cómo lo han aplicado a la educación familiar de sus hijos.

b) De 8:10 a 9:00, conferencia impartida generalmente por un especialista, $\mathrm{y}$ en otras ocasiones, por un par de monitores.

c) De 9:00 a 9:15, receso.

d) De 9:15 a 10:00, trabajo en equipos.

Los temas que se trabajaron fueron:

I. Introducción.

- Presentación del proyecto de escuela de padres.

— «Un alto en el camino. Reflexión personal sobre mi situación como persona, como pareja, como familia».

II. Relación de pareja.

1. Dignidad de la persona humana.

2. El valor de la vida.

3. Características del hombre y la mujer.

4. El amor humano entre la pareja.

5. Comunicación en la pareja.

6. Manejo del conflicto.

7. Sexualidad humana.

8. Sexualidad en la vida de pareja.

9. Cómo hacer para que la relación de pareja dure toda la vida. 
III. Educación familiar.

1. Esencia de la educación familiar.

2. El amor en la familia.

3. Relación entre padres e hijos.

4. Comunicación entre padres e hijos.

5. Formación de la conciencia ética.

6. Formación del carácter.

7. Educación de la sexualidad de los hijos.

8. Problemas sociales en la educación de los hijos: droga, alcohol, sexo, SIDA, entre otros.

9. Economía familiar.

10. Educación de los valores.

11. Educación de las virtudes humanas.

IV. Proyecto de vida.

1. Taller de diseño de proyecto de vida.

Como todo proceso educativo, se requirió de una evaluación para ponderar el logro de las sesiones. La evaluación se realizó por medio de una escala estimativa, que comprendía: excelente (10), muy bien (9), bien (8), regular (7) y mal (6). Los numerales se aplicaron para hacer el trabajo estadístico de la sesión. Los aspectos que comprendió la evaluación fueron los siguientes:

\section{A. La sesión:}

- Las preguntas iniciales fueron...

- La información presentada fue...

- El cumplimiento del horario fue...

- Considero que el tiempo asignado a la exposición es...

- La iluminación y recursos de exposición fueron...

- El aprendizaje obtenido fue...

B. Los expositores:

- La motivación durante la exposición me pareció...

- El dinamismo durante la exposición fue...

- El método expositivo fue...

- El domino del tema lo califico...

- Considero que los apoyos audiovisuales fueron...

- Pienso que la habilidad para exponer el tema fue... 


\section{El material:}

- La calidad del material proporcionado hoy, me parece...

- El contenido del material es...

- La organización del material de esta sesión es...

- Considero la utilidad del material como...

- La aplicación de la información a la vida cotidiana es...

D. La dinámica del grupo:

- El ambiente del grupo me parece...

- Califico la conducción de la dinámica por el monitor...

- Las conclusiones a las que llegó el grupo fueron...

- El tiempo asignado a la dinámica me pareció...

- Considero al aula de trabajo como...

- Califico la guía para la dinámica como...

E. Los servicios:

- El servicio de refrigerio me parece...

- El tiempo para el convivio lo considero...

- La organización del convivio es...

F. Los logros:

- La satisfacción de mis expectativas es...

- El cumplimiento de los objetivos presentados fue...

- Globalmente, el valor de esta sesión me pareció...

\section{¿QUÉ SUGIERO PARA}

\section{MEJORAR LA ESCUELA DE PADRES?}

¿Que resultados se obtuvieron al final del programa? En la parte cuantitativa, como se mencionó, se logró un $70 \%$ de asistencia general del grupo. El mayor número de participantes se encontró en el grupo de primaria menor y sobre todo en los grupos de $1^{\circ}$ y $2^{\circ}$. El de menor asistencia fue el grupo de $4^{\circ}$. El nivel de integración de los padres y madres de familia en los grupos fue mayor, generando sinergia para que otros padres se inscribieran en el siguiente programa. El taller de «Proyecto de vida» se llevó a cabo fuera de las instalaciones de la escuela y esto tuvo mucho éxito ya que los participantes se sintieron más cómodos para desarrollar los diferentes elementos del taller. 
Al final, cada monitor presentó una pareja o dos candidatos para que el próximo año escolar fueran monitores, con la finalidad de ser más numerosos y atender a más grupos con la logística que ello implica. Se les hizo la invitación al final del año escolar y en el mes de junio se reunieron los monitores que iniciaron, además de los invitados a formarse como monitores y el director de la escuela. En esta reunión, el director conformó un equipo directivo del proyecto de escuela de padres que tuviera continuidad para los próximos diez años. El equipo estaría compuesto por un presidente, un secretario, un tesorero y dos asesores (especialistas en temas de educación familiar). Para ocupar estos puestos se propusieron entre ellos mismos y por votación se eligió presidente, secretario y tesorero. Los asesores serían propuestos por la dirección. Dicho puesto se ocuparía por un período de tres años, es decir, tiempo suficiente para terminar la primaria menor y mayor durante cada gestión.

El modelo descrito se ha aplicado con sus correspondientes adaptaciones en las ciudades de Puebla, Mérida, San Luis Potosí, Aguascalientes, Fresnillo, y a nivel internacional en la ciudad de Santiago (Chile), Brasilia (Brasil) y Guatemala (Guatemala). El modelo ha sido promovido por el grupo de asesores que han estado desde su fundación en 1995.

Considero que la operación del modelo puede tener sus ajustes de acuerdo con la realidad de la escuela, sin embargo, con todos estos años de experiencia, el hecho de que los padres de familia participen de manera activa en la conducción de los equipos de trabajo ha sido la clave del éxito de este modelo de escuela de padres.

\section{BIBLIOGRAFÍA}

QUINTANA, José María, Pedagogía familiar, Editorial Narcea, Barcelona, España, 1995.

ESTEBES, María, Desarrollo organizacional, Editorial McGraw-Hill, México, 1996. 